\title{
Management of the psychological comorbidities of dermatological conditions: practitioners' guidelines
}

This article was published in the following Dove Press journal:

Clinical, Cosmetic and Investigational Dermatology

20 April 2017

Number of times this article has been viewed

\author{
Cody J Connor \\ Department of Dermatology, \\ University of Alabama at Birmingham, \\ Birmingham, AL, USA
}

\begin{abstract}
Dermatological disease can be devastating for patients, and although dermatologists are focused on remedying the cutaneous manifestations of these conditions, it is easy to miss the psychological suffering lurking below. Studies reveal that psychiatric comorbidity in dermatology is highly prevalent. Undetected psychopathology can greatly decrease a patient's quality of life and even contribute significantly to the clinical severity of their skin disease. For these reasons, it is vital that practitioners learn to detect psychological distress when it is present, and it is equally essential that they understand the treatment options available for effective intervention. Without training in psychiatric diagnosis and psychopharmacology, dermatologists can easily feel overwhelmed or out of their comfort zone when faced with the need to manage such conditions, but with the negative stigma associated with psychiatric disease in general, a psychiatric referral is often refused by patients, and the dermatologist is thus left with the responsibility. Uncertainty abounds in such situations, but this review seeks to alleviate the discomfort with psychodermatological disease and share practical and impactful recommendations to assist in diagnosis and treatment. In a busy dermatology clinic, the key is effective and efficient screening, combined with a repertoire of pharmacological and non-pharmacological treatment options that can be dispersed through an algorithmic approach according to the specific findings of that screening. By implementing these recommendations into practice, dermatologists may begin to gain comfort with the management of psychocutaneous disease and, as a specialty, may expand to fill a hole in patient care that is truly significant for patients, their families, and our communities as a whole.
\end{abstract}

Keywords: psychodermatology, psychopathology, treatment, screening, comorbidity, quality of life

\section{Introduction}

In the demanding world of dermatology, practitioners must endure the pressures of a busy clinic and the constant battle for efficiency to increase patient volume. Underlying it all, there lingers the desire to care for the patients in the best way possible: to ensure that their problems are fully addressed and that their health is not neglected as the practitioners seek the ultimate balance between quantity and quality. Skin is already the largest organ of the human body, and the breadth of pathology that it can present is enormous, but more and more, we are learning that the pathology in dermatology often extends deeper than the skin, into the very core of the patient - their mind. To add knowledge of such a complex concept to the already dynamic repertoire of a practicing dermatologist is a daunting proposal, but the necessity of this addition manifests itself daily in the faces of suffering patients struggling with dermatological
Correspondence: Cody J Connor Department of Dermatology, University of Alabama at Birmingham, $500 \mathrm{CEFH}, 1720$ 2nd Avenue South, Birmingham, AL 35294, USA

$\mathrm{Tel}+\mathrm{I} 2059342518$

Fax +l 2059345766

Email codyjconnor@gmail.com 
and psychiatric comorbidity. The following discussion seeks to elucidate the scope of this issue while sharing practical ways in which dermatologists can attend to the psychological needs of their patients.

\section{Dermatology and psychopathology}

"Psychodermatology" is a term used to describe the study of conditions that represent an overlap of dermatological and psychiatric pathology. This niche field has thrust itself into the spotlight over recent years, as practitioners increasingly identify the significant rates of such comorbidity and researchers further discover that physiological links may in fact underlie and contribute to co-occurring skin and psychiatric disorders. ${ }^{1,2}$ There are a number of conditions within the realm of psychodermatology, and in general, they can be classified into three distinct categories: primary psychiatric, secondary psychiatric, and psychophysiological. ${ }^{3-5}$

Primary psychiatric conditions are those that represent physical manifestations of a chiefly psychiatric problem. The types of underlying psychopathology include obsessive-compulsive disorder (OCD), anxiety, depression, and psychosis. Lesions are self-induced in response to these emotional disturbances, resulting in disorders like neurotic excoriations, acne excoriée, factitial dermatitis, habit-tic deformity, trichotillomania, and delusional infestation (DI; a broader term for delusions of parasitosis, which additionally encompasses a wider array of offending entities, including nonorganic agents like fibers or nanoprobes). ${ }^{3,4,6,7}$ Secondary psychiatric conditions are those that arise in response to the emotional distress of living with a disfiguring or highly symptomatic (pruritic or painful) dermatological disorder. These would include conditions like social anxiety and major depression, with possible inciting skin diseases such as psoriasis, acne, vitiligo, alopecia areata, ichthyosis, eczema, hidradenitis suppurativa, and so on. . $^{3,8-17}$ The third category of psychodermatological disease comprises the psychophysiological disorders - skin conditions that can fluctuate in clinical severity according to emotional state. This category includes conditions like atopic dermatitis, psoriasis, rosacea, alopecia areata, acne, telogen effluvium, and psychogenic urticaria. ${ }^{3-5}$ Many patients with these disorders report flares in response to stress or anxiety, and others find that their disease worsens when they are sad or depressed.

Although it is important to know that these psychocutaneous disease states exist, it is vital to also recognize just how common psychopathology is in the dermatological population. A recent multicenter study with $\sim 5,000$ subjects found rates of depression, anxiety, and suicidal ideation to be $10.1 \%, 17.2 \%$, and $12.7 \%$, respectively, in patients with skin disease compared with $4.3 \%, 11.1 \%$, and $8.3 \%$ in controls (odds ratios of $2.40,2.18$, and 1.94 , respectively). ${ }^{18}$ Psychological factors are thought to be involved in up to one-third of cases seen in dermatology clinics. ${ }^{4,5,19}$ Although this is a significant proportion of patients, some studies have suggested even greater rates of psychological disorder in particular conditions that are more specifically known to come with emotional sequelae. One study, for instance, used the Beck Depression Inventory (BDI) to discover depression rates as high as $54.5 \%$ in patients with vitiligo. ${ }^{8}$ In psoriasis, rates of depression from $12 \%$ to $24 \%$ have been shown, and anxiety rates up to $48 \%$, correlating with severity of psoriasis. ${ }^{9,10}$ Compared to the general population, hazard ratios for depression, anxiety, and suicidality in psoriasis patients have been reported at 1.39, 1.31, and 1.44 , respectively, with severe psoriatic disease associated with an even higher hazard ratio of 1.72 for depression. ${ }^{20}$ The magnitude of these figures may be shocking, but let this shock highlight how likely it is that these patients are passing daily through your doors, largely undetected, with underlying psychiatric distress that may be fueling their skin disease or amplifying their suffering in response to it.

\section{Psychological comorbidity and quality of life (QoL)}

The responsibility of physicians and care providers to the patients is to alleviate their suffering through the judicious use of pharmacological and non-pharmacological interventions. The act of specializing in medicine represents a decision to focus one's life on mastering a specific subset of human pathology, but it does not confer a sudden blindness to all other aspects of the patient that do not fall within that chosen realm. The patients come to physicians as whole individuals, and to treat them to the best of their ability, it often requires a wider lens through which to view their maladies. The patient's ultimate goal in seeking care is typically to feel better and to improve their QoL, and this chief objective should be shared by their care provider. Physicians should vigorously seek to achieve this goal by drawing on every ounce of medical knowledge in their repository and by utilizing every tool in their metaphorical toolbox. In dermatology, this rings as true as in any other specialty, for many of the skin conditions that patients must endure can confer deep psychological wounds and greatly impact their ability to live normal, happy lives.

Health-related quality of life (HRQoL) is an assessment of the extent to which one's health affects various aspects of his or her life, including psychological, social, physical, and cognitive functioning. Unfortunately, the effect of 
chronic skin disease on QoL often goes underappreciated. One study found that psoriasis causes a decrease in mental and physical functioning that is similar to other chronic and debilitating health conditions, such as depression, diabetes, chronic obstructive lung disease (COPD), heart disease, and cancer. ${ }^{21}$ More recently, researchers discovered similar findings for various chronic skin diseases, with comparable HRQoL impairments for non-dermatological conditions like COPD, cancer, liver disease, heart disease, and diabetes as were seen in patients with leg ulcers, hidradenitis suppurativa, prurigo, blistering diseases, psoriasis, atopic dermatitis, hand eczema, and several other dermatological diseases. ${ }^{22}$

In the pediatric population, Beattie and Lewis-Jones utilized two HRQoL measures - the Children's Dermatology Life Quality Index (CDLQI) and Children's Life Quality Index - to compare the impact of dermatological diseases to other chronic health conditions..$^{23}$ They discovered that, among skin diseases, children reported the most impairment with psoriasis (30.6\%) and atopic dermatitis (30.5\%), with urticaria (20\%) and acne (18\%) less so. Parents interpreted HRQoL deficits similarly, with atopic dermatitis imparting a $33 \%$ impairment, urticaria $28 \%$, psoriasis $27 \%$, and alopecia $19 \%$. Interestingly, researchers found that HRQoL impairments for other, chronic, non-dermatological diseases were comparable, including renal disease (33\%), cystic fibrosis (32\%), epilepsy (24\%), enuresis (24\%), and diabetes (19\%). Importantly, this negative impact on QoL does not seem to be limited to the patients themselves. Tollefson et al found that parents of children with psoriasis experience significant decreases in QoL, spanning several realms including personal well-being, family and social functioning, health and self-care, life pursuits, and, most significantly, emotional well-being. ${ }^{24}$ The intangible effects of skin disease, thus, may become a family-shared issue, as patient struggles translate to parental struggles and, presumably, to siblings as well.

These findings demonstrate how impactful chronic skin disease can be for patients and their daily function, and when truly pondered, it is not too hard to understand. Although patients with diabetes deal with a slew of additional worries because of their condition - dietary monitoring, oral and injectable medication management, frequent needle sticks for blood sugar checks and insulin administration, painful neuropathy, risks of heart disease, kidney disease, and vision deficits - patients with psoriasis might deal with shame and self-pity every time they look in the mirror, constant shedding of scales wherever they go, nagging joint pains, fear of taking their shirt off in public or showing too much skin on a job interview or a date, tolerating impolite stares or faces of confusion/disgust, ignorant people afraid that their condition is contagious, increased risk of heart disease and metabolic syndrome, and so on. ${ }^{25,26}$ The point is not to determine which of these conditions is objectively worse, as such a judgment will always be based in the subjective, but rather to realize just how much adversity patients must deal with day in and day out as a consequence of their skin disease. A 10-minute clinic appointment might not be enough to reveal the breadth of their suffering, but to automatically link this possibility with particular diagnoses, such as psoriasis, can go a long way in opening the clinician's mind, and bringing new opportunities for establishing rapport, uncovering important issues, and intervening in positive ways that can make huge differences for patients.

In psoriasis specifically, research suggests that current measures of disease severity, such as the Psoriasis Area and Severity Index (PASI), are not entirely reflective of the patients' self-assessment and do not necessarily correlate with how drastically the patients believe their disease is affecting them. ${ }^{27,28}$ This highlights the fact that subjective components of the individual's personality and internal psychology dictate the emotional response to the disease, allowing one patient to cope well with his/her PASI score of 20, whereas another may experience devastating depression and impairment in QoL with a milder PASI score of 5. Alternatively, another study found that psoriatic patients with completely clear skin reported lower Dermatology Life Quality Index (DLQI) scores, indicating less effect on their life, than patients with "almost clear" skin. ${ }^{29}$ Patients with clear skin were 50\%-60\% more likely to report that their disease had no effect on their QoL. This may be seen as a contradiction to previous findings indicating that disease severity is not directly correlated with QoL, but it may also represent a separate conversation altogether, as patients with clear skin may be interpreted as patients without psoriasis, and in general, it is well established that having psoriasis at all imparts a loss in QoL.

This discussion is clinically relevant, as it suggests that qualitative measurements of cutaneous disease severity may not be the end point by which to grade treatment success. Although these kinds of measures are helpful for determining whether a treatment is improving a patient's skin, they do not reliably express if the patient is happier. Variables, such as the side effects of treatment or the burden of utilizing the treatment, may in part account for this incongruence. As such, HRQoL may be a more appropriate primary end point, and HRQoL measures may be important tools for shedding light on the true "success" of treatment, appropriately taking into account factors that we cannot see 
with the naked eye and that are consequently not captured by tools like the PASI.

European guidelines, in fact, already consider HRQoL in making treatment decisions. ${ }^{30}$ They specify a treatment goal of at least PASI-75, meaning 75\% improvement in PASI score with treatment. If a treatment does not lead to at least a PASI-50, an alternative treatment should be pursued, and if a treatment leads to improvement somewhere between $50 \%$ and $75 \%$, they rely on the DLQI to guide them. They recommend modifying the therapy if a patient's DLQI is $>5$ - indicating a lower QoL - and continuing the current treatment if the DLQI is $\leq 5$. This seems to be a promising compromise between the use of objective disease severity measures and those of patient satisfaction, for it dictates the continuation of very effective treatments, the cessation of suboptimal treatments, and a more patient-centered approach for treatments that are moderately effective but may or may not be negatively affecting the patient's QoL through factors inherent in the specific therapy at hand. The author might suggest utilizing the DLQI in patients with a PASI-75 or greater as well, to ensure that scores are appropriately low as would be expected. An individual with a PASI-90 but a DLQI of 20 obviously needs further attention despite his/ her well-controlled skin disease, and this may involve altering the current treatment regimen among other things. Of course, such a scenario is only theoretical, but the possibility should indicate how widely applicable HRQoL tools are in dermatology and, indeed, medicine in general.

\section{Current outlook}

As previously touched upon, research continues to come out about the overlap of psychopathology and dermatology, and with it, we gain further insight into the extent of the mindskin connection. Even so, there remain questions of causality that must be understood, and further elucidation is necessary regarding the likely bidirectional relationship of psychological distress and cutaneous inflammation. ${ }^{1}$ It is clear that the amount we have to learn is vast, but while researchers seek to uncover the answers over the coming years, dermatologists can work to set the stage for their practical application. This can be accomplished by gaining and expressing an interest in the emotional experiences of our patients, by determining how best to identify those patients with psychiatric comorbidity, and by learning how dermatologists, without formal psychological/psychiatric training, can possibly help.

In the author's experience, a general sentiment that certain subsets of patients may be seen as "difficult" seems to exist. Those from the primary psychiatric category seem most prone for acquiring this label, as their underlying psychopathology is often more pervasive or striking. Sometimes, this translates into strange social skills that lead to predictably awkward interactions or maybe the patient insists on extended discussions requiring repetition of the same point multiple times, in various forms, before it is finally understood and/or accepted. Frustration with such exchanges is compounded by the need for efficiency when navigating a busy clinic, where a visit scheduled for 10 or 15 minutes can easily be extended to 30 , transforming the rest of the morning into a hectic game of catch up. It only takes one or two such encounters to pin a patient with that "difficult" tag, and from then on, the dermatologist may feel a subconscious feeling of heart sink when the patient's name appears on his/her clinic schedule.

The development of this internal stigma is nearly unavoidable, and while it does not necessarily translate into suboptimal care for these "difficult" patients, the potential for this consequence exists. As such, it is important to step back and think about what factors contribute to this scenario. Perhaps the most compelling reason is a lack of comfort with psychiatric disease. Dermatologists are specialized in skin, hair, and nails; their residency training does not include psychiatric diagnosis, psychotherapeutic principles, strategies of effective communication for patients with psychosis, or the art of diplomatic discussion with those in denial. Without this advanced training, and without the years of experience that a psychiatry residency imparts to our psychiatrist colleagues, dermatologists often feel entirely out of their comfort zone when confronted with these types of patients.

Ignoring the elephant in the room and focusing entirely on the skin (while avoiding the patient's emotional distress or clear psychopathology) may not only be quicker and less exhausting, but it also allows one to avoid facing the limitations of his/her knowledge. It is like a defense mechanism in itself: a paradoxical denial that there is something bigger going on, so that the physician does not find himself/herself suddenly thinking "I have no idea how to deal with this." No one likes to feel this way, and as physicians who have likely experienced a number of successes in life, perhaps we are a breed who finds this scenario even more unpalatable. But as physicians, our experiences have also revealed the importance of intentionally placing ourselves in such challenging situations, in testing the limits of our knowledge and - out of embarrassment, or shame, or whatever personal motivation may exist - expanding those limits through learning so that, perhaps, next time we have the answer as if it's been there all along. The question, now, is how to appropriately and efficiently detect and treat psychopathology in a dermatology 
clinic. The answer, as will be discussed, is centered on integrated care.

\section{Integrated care}

The first step in solving any problem is identifying that it exists. Outside of a clinician's intuition, many dermatology clinics do not have any methods in place for recognizing psychological distress in their patients. As this discussion has outlined thus far, it is vital to recognize this, as undetected psychopathology can wreak tremendous suffering on patients, and the prevalence of this is significant.

When a patient with a primary psychiatric disorder, such as DI, arrives at a dermatologist, it is the skin condition - the numerous excoriations, scars, and angulated, open sores at various stages of healing - that is initially most salient, and without a good history (or recognition of suggestive lesion patterns, such as absence of lesions on inaccessible areas like the mid-back), the underlying psychiatric disorder may go completely unnoticed. Alternatively, a keen provider may pick up subtle hints of anxiety or psychosis throughout the patient interaction, or possibly the root issue may be as blatant as the skin findings themselves. In primary psychiatric conditions, conventional dermatological treatments will likely fail to resolve the cutaneous symptoms, and extended therapeutic courses can be fruitlessly pursued if the underlying issue is not discovered and appropriately addressed.

For patients with secondary psychiatric disorders, the psychological condition (eg, generalized anxiety, depression, and social anxiety) will almost certainly be overshadowed by the skin disease (psoriasis, eczema, etc). As such, detection may be extremely difficult without a high index of suspicion along with the impetus to delve further into the possibility, and the knowledge as to how. Patients in these situations may underplay or deny their mood symptoms, or they may not even recognize their presence, often so focused on their skin that they do not notice how anxious or depressed they have become. With the chronic nature of many skin diseases in this category, it is even possible that patients may grow so habituated to their emotional state that they can no longer detect just how far from normal it is.

When patients do not raise the concern themselves, it undoubtedly makes it harder to know that the problem exists. This common scenario highlights how significant suffering can go unnoticed and untreated, and how simple screening interventions may go a long way in making a meaningful difference. There are many various screening tools available for the detection of psychiatric disorders, and the key here is choosing a test that is easily implemented into an outpatient clinical setting, either self-administered by the patient or reliably administered by a medical assistant, and supported by the literature as sensitive and reliable. Such a tool could potentially be printed and provided to patients in the waiting room, as many clinics already do with the review of systems. This would be a simple addition to make, and it should not lengthen the patients' visit too extensively, particularly if completed while waiting to be roomed.

Of course, a positive screen should prompt further discussion of the noted issue, but the value of this additional care may be tremendous. This benefit could be multifaceted, including increased rapport with patients (and more wordof-mouth marketing by satisfied customers), appropriate guidance of therapeutic interventions based on the underlying disorder uncovered, quicker resolution of the patients' dermatological problems and improved patient QoL (if correct treatment is provided), and more satisfaction from the physician, knowing that they treated their patient as a whole, and that they truly and effectively practiced the art of healing to the best of their ability.

One study revealed that dermatologists are not very good at detecting psychological distress in their patients, nor are they frequently pursuing concerns and discussing them further during the visit. ${ }^{31}$ In this study, 43 consultations between dermatologists and patients were analyzed, revealing that physicians were only able to detect anxiety and depression reported by patients in about one-fourth of cases (kappa statistic of 0.24 for anxiety and 0.26 for depression, where kappa is a measure of inter-rater agreement, taking into account the possibility of agreement occurring simply by chance). In only $39 \%$ of consultations involving psychologically distressed patients did the dermatologist raise a concern and explore the issue. Physicians might refute these results as applying personally to their practice based on their own confidence in empathizing with their patients, but this study actually had participating dermatologists fill out the Jefferson Scale of Physician Empathy, and the analysis revealed that empathy scores had no effect on accuracy of psychological assessment. As humans, without formal training, and with time constraints and other pressures at play, we are simply not great at detecting psychological problems in our patients. We must thus rely on formal tools to assist us in this important endeavor.

\section{Screening}

As previously established, it is important not only to detect the presence of psychological distress, like depression and anxiety, in patients with skin disease but also to measure 
HRQoL to determine disease impact and guide treatment decisions. For anxiety and depression, many options are available. For practical screening in an outpatient setting, the Beck Depression Inventory II (BDI-II) and Patient Health Questionnaire-9 (PHQ-9) are great options.

The BDI-II is a 21-item, multiple choice, self-report screen designed for use in patients aged $\geq 13$ years. Each question is graded from 0 to 3 , and the individual scores are then summed to obtain on overall depression score. Overall scores ranging 0-13 indicate minimal depression, 14-19 mild depression, 20-28 moderate depression, and 29-63 severe depression. This is a reliable and well-validated tool that is widely used for depression screening in primary care. ${ }^{32,33}$ A correlate for children, called the Children's Depression Inventory (CDI), is a 27-question self-report screen for patients aged 7-17 years, which has shown good validity as well, but discordance between child and parent reports has raised some questions about the utility of self-report screens in younger children. ${ }^{34,35}$

The PHQ-9 is a 9-question screen based on the diagnostic criteria delineated in the Diagnostic and Statistical Manual of Mental Disorders (DSM). Like the BDI-II, it is a short, self-report questionnaire that has shown high reliability and validity and is widely used across the world. ${ }^{36}$ Studies comparing the BDI-II and PHQ-9 have revealed that both tools yield highly similar results, meaning they are virtually interchangeable for depression screening purposes in the primary care setting. ${ }^{37,38}$ In determining which of these tools to utilize, it is significant to note that the PHQ-9 is not only shorter in length but also in the public domain and, therefore, free to use. This is not the case for the BDI-II.

The Generalized Anxiety Disorder-7 (GAD-7) is a wellvalidated screen for anxiety, which is similar to the PHQ-9 in that it is based on DSM diagnostic criteria, and it is short (7 questions), free to use, and self-administered. ${ }^{39,40}$ Another possible option is the Hospital Anxiety and Depression Scale (HADS). The HADS has been widely used for research purposes, revealing significant reliability and usefulness in screening for anxiety and depression in hospital outpatient populations. ${ }^{41-43}$ It is a questionnaire composed of 14 items ( 7 for anxiety and 7 for depression) that apply to the preceding 7 days and that are graded $0-3$, yielding a score from 0 to 21 for each depression and anxiety. Scores ranging 8-10 indicate "mild" anxiety, 11-15 are "moderate," and $\geq 16$ are "severe." Although this tool is a reliable and convenient means of screening for both anxiety and depression, it is intended to be administered by an interviewer, meaning a physician or trained assistant would need to read the questions to the patients rather than providing a printed questionnaire for them to complete on their own. In addition, the HADS is a copyrighted test that must be purchased for lawful reproduction and use. A more practical approach for a busy dermatology clinic may thus involve printed PHQ-9 and GAD-7 questionnaires to be completed by patients in the waiting room prior to their appointments.

For HRQoL measures, again a slew of options from which to choose exist, which include tests for use in dermatological patient populations specifically and even more specific tests tailored to the particular skin disease the patient has, such as psoriasis. ${ }^{44}$ Some reasonable options for use in dermatology include the Dermatology Life Quality Index (DLQI), Dermatology Quality of Life Scales (DQOLS), Skindex, and, for children, the Children's Dermatology Life Quality Index (CDLQI). The DLQI has been the most widely used HRQoL measure in the dermatology literature - used in $>40$ different skin conditions, in $>80$ countries, 90 languages, and described in $>1,000$ publications - and thus is validated and reliable in this population. ${ }^{45}$ It is a short, self-administered questionnaire composed of 10 questions about symptoms and feelings, personal relationships, daily routines, functioning at school/work, leisure activities, and treatment. Answers are based on the previous 7 days, with scoring on a 4-point Likert scale from 0 to 3, with 0 representing "not at all" and 3 "very much." Summing the individual questions produces an overall score from 0 to 30 , with a higher number correlating to more HRQoL impairment. A score of $0-1$ represents no effect on HRQoL, 2-5 signifies small effect, 6-10 moderate, 11-20 very large, and 21-30 extremely large. Of note, when using the DLQI to follow a patient throughout treatment of an inflammatory skin condition, a change in score of 4 points has been determined to represent a clinically significant shift. ${ }^{46}$

The CDLQI may be a good option for pediatric dermatology patients, whereas the DQOLS and Skindex, though validated measures, are more intensive than the DLQI, at 41 questions and 61 questions, respectively. ${ }^{44,47,48}$ Some disease-specific HRQoL measures include the Psoriasis Disability Index (PDI) and the Psoriasis Life Stress Inventory (PLSI). ${ }^{44,45,49}$ The PDI is originally 10 questions in length, but there is a modified 15-question version available. One group of researchers suggested that a few questions should be removed from the 15 -item version to increase the specificity for psoriasis, as these questions dealt with other skin conditions such as eczema and urticaria. ${ }^{50}$ The PLSI is also a 15-question screen, which may be improved upon by the deletion of three items to increase internal reliability. ${ }^{51}$ These items are 7 - fear of having serious side effects from medical treatments; 11 - not enough money to pay medical bills; and 
14 - hairdresser appearing reluctant to cut your hair. Although both the PDI and PLSI are good measures for HRQoL in psoriasis, they differ in that PDI has been shown to correlate with psoriasis severity (PASI), whereas the PLSI is seemingly independent of clinical disease severity. ${ }^{51,52}$

For simplicity, the DLQI is a short and well-established HRQoL tool that can be used across all dermatological diseases, and adding use of this to one's practice would be a good first step for those looking to begin expanding their patient care to include psychological awareness. When utilized in a clinical setting, the DLQI is free to use, which adds to its appeal. Psoriasis-heavy clinics may experiment with the more disease-specific tests available and possibly consider using the DLQI as well for further information and monitoring purposes.

\section{Treatment}

The simplest solution for addressing a true psychiatric concern would be prompt recognition of the problem and appropriate referral to a psychiatrist, who is specially trained to deal with these important issues. Unfortunately, the simplest solution is not always possible. Although the first part of the equation - problem recognition - can be accomplished by practicing psychological awareness with patients and by utilizing the screening tools discussed earlier, the second part may be difficult to obtain in practice, as patients may be unwilling to follow through with psychiatric referral. There are many potential reasons why patients might not be accepting of their need to see a mental health professional.

It is possible that the patient may not realize that a psychiatric disorder is the underlying cause of their skin condition, and even after ample counseling on this point, denial may be a potent defense mechanism. It is also possible that loss of motivation, for instance in patients with secondary major depression, may hinder individuals from committing any more time to doctors than they already have by visiting the dermatologist. In addition, and as briefly mentioned earlier, many patients may not even recognize that they are suffering from a mood disorder because they have lived with their skin condition and the associated emotions for so long that it has become "normal." In such cases, patients may not raise the issue themselves, and this confers a high risk of missed diagnosis if screening tools are not set in place to catch the problem, and a concerned provider present to appropriately highlight the need for intervention.

The negative stigma associated with psychiatric illness and those that seek psychiatric care is also a powerful deterrent, and patients may be unwilling to accept medication from psychiatrists that they would otherwise be happy to take if only prescribed by their dermatologists. ${ }^{53,54}$ Because it may be difficult to convince a patient to seek professional mental health care, there is an important hole that dermatologists can potentially fill by learning a few basic management strategies for the treatment of psychiatric illness in their patients.

A good first step is to have an honest conversation with the patient about the suspicions of underlying or comorbid psychopathology. Referencing any screening tools used can be helpful in demonstrating the reasoning behind the conclusions. For apparent psychophysiological conditions, it is important to briefly discuss how studies have allowed us to recognize the role of psychological distress in worsening particular skin diseases. By revealing this logic, patients may then arrive at their own conclusions by recognizing that psychiatric treatment to stabilize mood should theoretically prevent the anxiety or depression that can cause exacerbation. It is always easier to convince patients to accept treatment if they are the one who has decided it is necessary. This is basically motivational interviewing, that is, a form of counseling in which the counselor assists the patient in recognizing goals and barriers and, in a non-judgmental way, facilitates the patients in identifying appropriate solutions to reach their goals. ${ }^{5,56}$ In this case, the goal would be clear skin, and the barrier would be stress or depression.

With psychophysiologic conditions, however, it is important to determine whether the patient's distress is mainly somatopsychic or psychosomatical in nature. ${ }^{5}$ Somatopsychic means that the patient's anxiety or depression stems from the severity of their skin disease. In such a case, the true solution lies in altering the current treatment regimen to gain better control of the skin condition, possibly by changing to more potent topical medications or even starting systemic agents, if necessary. Conversely, "psychosomatic" refers to a flaring of skin disease in response to environmental stresses, like the death of a family member or an upcoming exam or job interview. In this case, the skin condition is worsened by maladaptive emotional responses from the patient, and the solution lies in improved stress management or referral for counseling, such as cognitive behavioral therapy (CBT), to attempt to change the patient's psychologically harmful reactions to external stressors. Although this binary construct can be useful in deciding where to begin when addressing a patient's psychological and dermatological comorbidity, in reality, the association between the skin and the psyche is much more complex, with evidence supporting a bidirectional relationship between emotional state and cutaneous inflammation, making it difficult to determine which disturbance came first. ${ }^{1}$ 
In the pediatric population, it is intriguing to consider the possible effects that parental psychology might have on the patients' skin. Particularly in young children, cognition may not yet be advanced enough to allow for feelings of social anxiety, self-pity, or hopelessness that often feed into the emotional milieu of an adult with dermatological disease, but a young child could very well be capable of interpreting an anxious parent who is upset with the complexities of having a child with eczema, including the doctor visits, the financial burden of purchasing medications and moisturizers, and the time and effort required to apply these products in a consistent and effective manner. Thus, although a child's skin may not directly cause distress, it may affect the child indirectly through the emotional responses of his or her parents, possibly leading to subsequent disease flares. Some studies have effectively demonstrated this dynamic by revealing that parental counseling aimed at increasing insight and fixing flawed parent-child relationships can lead to significant improvement in eczema when compared to those not receiving such supplemental interventions. ${ }^{57-59}$ In adults with eczema, psychotherapy aimed at helping patients to identify and constructively deal with life stresses has also shown benefit for decreasing disease severity when used as an adjunct to standard treatment. ${ }^{60}$ Similar findings have been observed in patients with psoriasis, where supplemental psychotherapeutic interventions have resulted not only in improvements in HRQoL scores and subjective measures of anxiety/depression but also in reductions in psoriasis severity. ${ }^{61,62}$

If counseling is ineffective or refused outright by the patient, psychoactive medication may be indicated, depending on the presence and severity of physiological symptoms (eg, hyperventilation, tachycardia, and chest pains) and the functional impairment experienced..$^{5}$ For many dermatologists, this might mean referral to psychiatry or discussion and coordination with a patient's primary care provider (PCP). Some providers have even established combined dermatology-psychiatry clinics to which to refer these patients, where both a staff dermatologist and psychiatrist are on hand to work in coordination for the benefit of the patient. This setup may not only increase clinician confidence and patient convenience but also ultimately result in lower health care costs and improved outcomes. ${ }^{63-65}$ If factors like patient resistance or lack of a PCP render these options unrealistic, then consideration of personally managing the patient's psychological distress may be in order. This should not be considered outside the realm of expectation, as the root motivation for treatment of the mind, in this situation, would be treatment of the skin. Indeed, it is advantageous to constantly seek expansion of one's repository of familiar treatment options, as this amounts to growth as a clinician and allows for increasing ability to satisfy patients in need.

While deciding which psychopharmacological agent is most indicated for treating a patient, it is important to first determine the underlying psychopathology present. ${ }^{5}$ This means identifying if the root issue is anxiety, depression, obsession/compulsion, or psychosis, as each of these classes of psychological disorder have their own set of viable treatment options. Correct diagnosis is not always as simple as determining what psychodermatological condition you're dealing with, as many of these disorders can be associated with one of multiple psychological causes. For instance, the most common underlying cause of trichotillomania (incomplete hair loss secondary to impulsive pulling of one's own hair) is obsessive-compulsive behavior, but other possibilities include mental retardation, anxiety, depression, reaction to situational stress, and trichophobia, a rare disorder in which the patient maintains a delusional conviction that the roots of the hairs contain a foreign entity that must be removed to allow for normal hair growth. ${ }^{3,66}$ In cases of trichotillomania, the patient interview is vital in providing the details suggestive of one cause versus the other. An admission by the patient that they pull their hair when they are nervous is more indicative of situational stress response or generalized anxiety, whereas a description of incessant thoughts about hair pulling, accompanied by a mounting feeling of anxiety that is only relieved by the act of hair pulling, is certainly classic for obsessive-compulsive origins. ${ }^{66}$

\section{Anxiety}

For treatment of anxiety - whether it is a secondary psychiatric disorder in response to severe psoriasis, an exacerbating factor in a psychophysiological disorder like eczema, or an underlying motivator for a primary psychiatric picking disorder like neurotic excoriations - there are multiple medication options that, for decades, have been widely used by psychiatrists and PCPs alike. One class of anxiolytics is the benzodiazepines. These medications have relatively quick onset of action, with various options offering durations of effect ranging from short to longer acting. Because of the quick onset, gratification is easily associated with this medication, and this class of drugs can be very addictive, particularly if used for extended periods of time. ${ }^{67}$ Risks of sedation and respiratory depression also accompany these medications, and withdrawal seizures are a dangerous and potentially life-threatening risk of abrupt discontinuation following long-term use. Because of these characteristics, 
benzodiazepines are best suited for use on an as-needed basis. Alprazolam is one of the most widely used benzodiazepines, and it has been found to confer a unique antidepressant effect, unlike other benzodiazepines, which typically tend toward the opposite. ${ }^{68-70}$ Thus, for an individual with a mix of depressive symptoms and situational anxiety, alprazolam may be a good option.

Starting at a low dose is always a good option, and titrating slowly upward until reaching the minimal effective dose is important in avoiding excessive sedation and limiting risk. A typical starting dose is $0.25 \mathrm{mg}$ three times a day (TID), with an ability to increase the dose every 3-4 days up to a maximum of $4 \mathrm{mg} /$ day. One expert reports starting even lower, at $0.125 \mathrm{mg}$ (half of a $0.25 \mathrm{mg}$ tablet) TID, and titrating up to a maximum of no more than $2 \mathrm{mg} /$ day, with a typical effective regimen consisting of $0.25-0.5 \mathrm{mg} \mathrm{3-4}$ times per day. ${ }^{5}$ An additional recommendation is to limit benzodiazepine use for 2-3 weeks duration unless a psychiatric referral has been made and extended treatment approved, and this author would agree that such a restriction is important, particularly for providers who are not used to managing this medication long-term. Of note, alprazolam is particularly addictive due to its rapid onset and short duration of action. ${ }^{67}$ Use of a longer-acting benzodiazepine, such as clonazepam, has been suggested as a reasonable alternative. ${ }^{71}$ Although clonazepam does not confer the same antidepressant effect, it is less addictive and may be better suited for patients with strict situational anxiety and no signs of depression. This medication can be started at $0.25 \mathrm{mg}$ twice a day (BID) and increased every 2 days up to $0.5 \mathrm{mg} \mathrm{TID}$, with a maximum dose of $4 \mathrm{mg}$ /day, though as with alprazolam, a maximum of $2 \mathrm{mg} /$ day may be more practical for dermatologist prescribers. Once again, benzodiazepines are best suited for short-term use, and as such, they are commonly used for managing anxiety while safer, more long-term but slower-acting treatments (such as those discussed later in text) are taking time to affect the physiological changes needed for therapeutic benefit. ${ }^{71}$

Another type of anxiolytic is a medication called buspirone, which is classified as a non-benzodiazepine anxiolytic, meaning that it does not carry the same risks of addiction, withdrawal, and sedation. ${ }^{72}$ This medication is typically prescribed to treat GAD and is not fit for as-needed or situational use because its effects can take at least 2 weeks to appear. The starting dose for buspirone is $5 \mathrm{mg}$ TID or 7.5 mg BID. Because of its linear pharmacokinetics and short half-life, it is possible to increase the dosage by $5 \mathrm{mg}$ /day every 2-3 days until a target of $20-30 \mathrm{mg}$ /day, divided into two or three daily doses, is reached. ${ }^{73}$ If, after several weeks, adequate clinical improvement has not been obtained, it is possible to titrate up to a maximum dosage of $60 \mathrm{mg} /$ day. The side effect profile for buspirone is relatively mild, with common symptoms like gastrointestinal (GI) disturbances (nausea, vomiting, and diarrhea), sleepiness, fatigue, lightheadedness/dizziness, and headache. ${ }^{72,74}$

As another alternative, the selective serotonin reuptake inhibitors (SSRIs), escitalopram and paroxetine, are also approved for the treatment of GAD. ${ }^{75}$ SSRIs are first-line antidepressant medications that have been used safely for many years, with common adverse effects including GI disturbances, sexual dysfunction, and somnolence, and more serious possible reactions like serotonin syndrome, paradoxical increased suicidality, syndrome of inappropriate antidiuretic hormone secretion (SIADH). In direct comparison, escitalopram has shown superiority over paroxetine and has demonstrated long-term efficacy and safety in the treatment of GAD. ${ }^{76-78}$ Escitalopram can be started at $10 \mathrm{mg} /$ day and increased after 1 week to the maximum of $20 \mathrm{mg} /$ day. Both the doses have shown effectiveness and good tolerability. As escitalopram is an antidepressant, unlike benzodiazepines and buspirone, an additional risk is the potential for triggering a manic episode in a patient with bipolar disorder. It is thus important to ensure that there is no history of mania prior to starting a patient on escitalopram or any other antidepressant.

\section{Depression}

For some individuals with depression, irritability and psychomotor agitation can be prominent features, and these can contribute to the development of primary psychiatric conditions like neurotic excoriations, factitial dermatitis, and acne excoriée. Doxepin is a tricyclic antidepressant (TCA) medication that has shown great utility in treating these types of patients. ${ }^{79}$ The reason why doxepin is unique among the other numerous antidepressants is that it demonstrates potent antihistamine effects, resulting in decreased itching. ${ }^{80-82}$ The antihistamine effects may also cause drowsiness, so the medication is often recommended for use at bedtime. Doxepin can be started at $25 \mathrm{mg}$ / day and increased by $25 \mathrm{mg}$ every 5-7 days until reaching the ideal therapeutic dose, typically between 100 and $300 \mathrm{mg} /$ day. ${ }^{5}$

As a TCA, doxepin comes with all the classic side effects and risks that this drug class carries, including anticholinergic symptoms (dry mouth, urinary retention, blurry vision, tachycardia, etc), cardiac conduction problems, and orthostatic hypotension. TCAs are potentially lethal in overdose, so be sure to ask directly and explicitly about suicidal or self-harm thoughts. Any suspicion of suicidality in a patient should elicit appropriate caution in prescribing, making sure to avoid providing an 
excessive number of tablets beyond what is necessary to last the patients until their next appointment. Closer follow-up (more frequent visits) may also be warranted. Fortunately, it is possible to check the serum levels of doxepin, and this can be useful not only in investigating potential cases of overdose but also in confirming patient compliance with treatment and determining whether therapeutic levels have been reached. ${ }^{83,84}$

For other depression variants, SSRIs are typical first-line medications due to proven effectiveness and overall better safety and tolerability compared to alternative antidepressant classes like TCAs and monoamine oxidase inhibitors. Serotonin-norepinephrine reuptake inhibitors (SNRIs) are also a first-line option, and some studies have demonstrated the SNRI, venlafaxine, to be particularly effective in melancholic depression and patients with significant psychomotor retardation. ${ }^{85,86}$ The SSRIs fluoxetine and sertraline are often considered to be more "activating" options in this class, making them good for melancholic depression as well, with sertraline demonstrating better effectiveness and better tolerability. ${ }^{87-89}$ In fact, one large meta-analysis concluded that sertraline is the overall best option for initial treatment in patients with moderate to severe depression, as it has the best balance of effectiveness, tolerability, and cost. ${ }^{88}$ Sertraline can be started at $50 \mathrm{mg} /$ day and increased every week by $25 \mathrm{mg} /$ day up to the maximum of $200 \mathrm{mg} /$ day, if necessary. Some psychiatrists start at an even lower dose (12.5 or $25 \mathrm{mg} /$ day) and expect to see benefits by $100 \mathrm{mg} /$ day, in most cases.

SSRIs and SNRIs are widely prescribed and overall safe options that dermatologists can feel comfortable prescribing, but in cases where discomfort is too high, the over-the-counter herbal supplement, St. John's wort (hypericum perforatum) has demonstrated effectiveness in mild-to-moderate depression. ${ }^{90-93}$ Adverse effects are uncommon (2.4\%) and mild, including GI upset, headaches, and insomnia. ${ }^{90}$ Although effective and well-tolerated, it does affect the metabolism of various other drugs by acting as an inducer of the cytochrome p450 34A enzyme. ${ }^{94}$ This activity can lead to decreased serum levels of other medications, like alprazolam, for instance. For this reason, St. John's wort is contraindicated in patients taking cyclosporine to prevent organ transplant rejection or GVHD, as blood levels of cyclosporine can drop dangerously low and lead to serious consequences. ${ }^{90}$ Careful review of the patient's medication list is thus necessary before recommending St. John's wort, but this is a good alternative to prescription of antidepressants for those with mild disease.

\section{Psychosis}

Psychosis is the chief underlying psychopathology in psychodermatological disorders like delusions of parasitosis, in which patients maintain the fixed, false belief (delusion) that parasites reside within their skin and must be picked out. ${ }^{95}$ Such delusional conditions are part of a subset of psychosis called monosymptomatic hypochondriacal psychosis (MHP), in which the delusions are confined and far less pervasive and impairing than the psychotic symptoms of conditions like schizophrenia. ${ }^{95,96}$ In dealing with patients suffering from delusional beliefs, it is important to be accepting and non-argumentative in order to establish rapport. ${ }^{5,97}$ This means willingness to examine evidence and expression of open mindedness. The clinician must, at the same time, avoid validating or reinforcing the patient's false beliefs. ${ }^{5}$

Prior to prescribing psychotropic medications, it is imperative that the clinician determines whether or not the patient's symptoms are stemming from actual organic origins. A patient with suspected DI, for instance, may have an actual infestation with scabies or lice (careful examination and skin scraping, of course, are vital), or they may experience formication (the sensation of biting or crawling on the skin) as a result of recreational drug abuse with amphetamines, cocaine, alcohol, or other illicit substances. Other potential causes include vitamin B12 deficiency, cerebrovascular disease, multiple sclerosis, Parkinson's disease, syphilis, hypothyroidism, diabetes, cancer, and iatrogenic. ${ }^{3,64,98}$ Dopaminergic medications prescribed for Parkinson's disease, including ropinirole and piribedil, have been identified as causes of DI in several cases. ${ }^{98,99}$ Ruling out these triggering factors is important, as only primary DI (caused by true delusion/psychosis) is treated with antipsychotics, whereas secondary DI (that which has an organic basis) is treated by addressing the underlying issue. Ruling out substance abuse may require more than simply asking the patient whether they use drugs, as substance abuse seems to be quite prevalent in this patient population, and they do not always openly disclose the habit. ${ }^{100}$ As a result, routine urine drug screens may be recommended for new patients with DI, even if they deny drug use. ${ }^{64,100}$

Pimozide is a typical, first-generation antipsychotic that has classically shown effectiveness in treating MHP in dermatological patients, particularly delusions of parasitosis. ${ }^{95,96,101-104}$ The starting dose is $1 \mathrm{mg}$ /day and can be increased by $1 \mathrm{mg}$ every week. The maximum dose is $10 \mathrm{mg} /$ day, but patients with MHP typically show good response at doses of $4 \mathrm{mg}$ /day or less. ${ }^{5}$ Extrapyramidal symptoms, such as dystonia and parkinsonism, are possible and can be combatted with benztropine mesylate (Cogentin) taken 1-2 mg BID or diphenhydramine taken $25 \mathrm{mg} \mathrm{3-4} \mathrm{times}$ a day. ${ }^{105}$ Cardiac conduction abnormalities have also been reported, with electrocardiographic changes such as T-wave 
abnormalities and QT interval prolongation, so a baseline electrocardiogram is recommended prior to starting pimozide and again after treatment has begun. This may be completed in coordination with the patient's PCP, and if concern such as QT prolongation is present, the medication should not be started or should be discontinued. Drug-drug interactions are also possible, particularly with medications that are metabolized by cytochrome P-450 isozyme $3 \mathrm{~A} 4 .{ }^{65}$

Although pimozide has historically been the go-to medication for DI, the development of second-generation atypical antipsychotics (SGAs) has shifted attention onto these newer, safer agents, which are known to cause fewer extrapyramidal and anticholinergic side effects ${ }^{65,106}$ Although a large meta-analysis of $>1,200$ cases revealed effectiveness of antipsychotics in DI, with $\sim 50 \%$ rate of full remission, this study was published before the era of SGAs. ${ }^{107}$ A more recent, comprehensive investigation into the effectiveness of SGAs identified 63 published cases of DI in which SGAs were used, demonstrating that partial or full remission was obtained in $75 \%$ of patients. ${ }^{65}$ Olanzapine and risperidone were the most widely used agents.

Other atypical antipsychotic options recommended for the treatment of DI include quetiapine, amisulpride, and the so-called third-generation antipsychotic, aripiprazole..$^{64,108,109}$ Doses of these medications (risperidone $0.5-1 \mathrm{mg}$ daily; olanzapine $5 \mathrm{mg}$ daily; quetiapine $50 \mathrm{mg}$ daily; amisulpride $50 \mathrm{mg}$ daily; and aripiprazole $5 \mathrm{mg}$ daily) are lower for DI than for more pervasive psychotic conditions like schizophrenia, and routine lab monitoring is not typically necessary. ${ }^{64}$ Due to the risks of cardiotoxicity and drug interactions with pimozide, these agents have now replaced pimozide as first-line treatment for DI. ${ }^{64,65}$ Of note, the SGA clozapine was not included in this recommended list, as this medication requires frequent blood count monitoring due to risk of agranulocytosis. In addition, it is important to recognize that almost all antipsychotic agents can cause weight gain and/or metabolic syndrome, with olanzapine and clozapine posing the greatest risk, and amisulpride and aripiprazole with little to none. ${ }^{110}$ As an interesting side note, studies have determined that this weight gain is mediated through an antagonistic effect on histaminergic $\mathrm{H} 1$ receptors (H1R), and the commonly prescribed H1R agonist and anti-vertigo drug, betahistine, is able to safely and effectively mitigate antipsychotic-associated weight gain. ${ }^{111-113}$

Although it may be difficult to convince a patient to try an antipsychotic medication, returning to motivational interviewing techniques can be effective. Presenting the medication as an attempt to decrease agitation or uncomfortable sensations (rather than explicitly stating that it will treat psychosis or improve the patient's skin) may be worth a try. ${ }^{5}$ In addition, one expert explains to the patient the importance of treating their condition from the outside-in (with topical medications and creams, such as mupirocin and moisturizers) as well as the inside-out (with medication), stressing that successful treatment truly requires both routes of attack. To support patient compliance, it is useful to note that these medications take 6 weeks to start working, and peak effect is not expected until 6 months after starting. ${ }^{64}$ If treatment is effective and patient experiences remission of DI, it is reasonable to attempt weaning off of the antipsychotic starting 3 months after remission is obtained, with plan to restart if relapse occurs. The highest risk of recurrence is within the first 3-4 months following discontinuation of antipsychotic therapy, with $\sim 25 \%$ of patients experiencing return of symptoms requiring longer treatment courses or possibly long-term maintenance therapy. ${ }^{114}$

Although prescription of antipsychotics is not a typical activity for dermatologists, some have argued that it should be, particularly since MHP patients differ drastically from the more globally affected individuals seen by psychiatrists. ${ }^{103}$ Antipsychotic treatment can lead to a happy patient whose disease is well-controlled instead of a seemingly hopeless, "difficult" patient who continually rotates through your clinic without any sign of improvement despite ample and repetitive counseling. It represents an opportunity for dermatologists to truly take charge of their patients' health and to adeptly focus their efforts on the root cause of the skin condition for which the patients seek care.

\section{Obsessive-compulsive}

The last conditions to discuss are those based in obsessivecompulsive behavior. While referral for psychological counseling - such as CBT, exposure and response prevention, or other behavioral modification therapies - can be extremely effective and should be considered first-line, patients can be resistant to these options or may fail to respond, in which case psychopharmacological interventions are necessary. ${ }^{15-117}$ Clomipramine is a TCA that has shown superiority in its class for the treatment of OCD and related conditions, such as trichotillomania and onychophagia (nail biting). ${ }^{118-121}$ Clomipramine is started at $25 \mathrm{mg} /$ day and can be titrated up to $250 \mathrm{mg}$ /day if needed. ${ }^{122}$ For children, the maximum dose is $3 \mathrm{mg} / \mathrm{kg} /$ day. Side effects are similar to other TCAs as previously discussed, with slightly more occurrence of seizures (lowers the seizure threshold) and sexual dysfunction. ${ }^{122}$

Fluoxetine is an SSRI alternative for OCD, which has shown similar efficacy and has been successful in treating dermatological conditions like habit-tic deformity of the 
nail. ${ }^{123,124}$ It is prescribed at $20 \mathrm{mg} /$ day and can be increased to $80 \mathrm{mg}$ /day maximum if necessary, although $20-40 \mathrm{mg}$ /day is typically effective. As with other SSRIs, effects may not be noticed for a few weeks, and peak benefit may take 6-8 weeks. Of note, fluoxetine is FDA-approved for depression but not OCD, so use in this condition would be off-label.

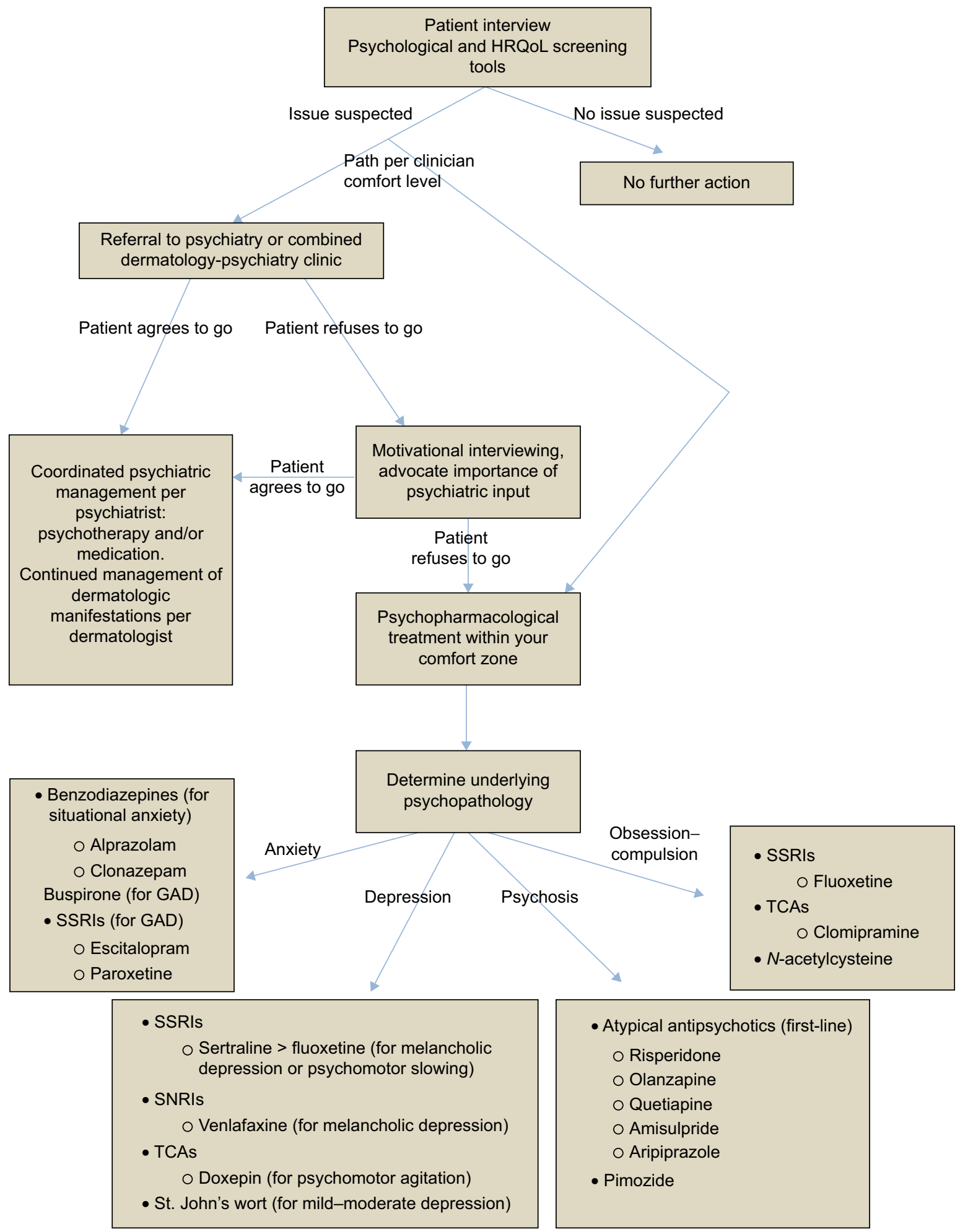

Figure I Approach to the treatment of psychiatric comorbidity in dermatology.

Notes: This is an algorithmic approach to the detection and treatment of psychodermatological disease based on the information reviewed in this paper.

Abbreviations: GAD, generalized anxiety disorder; MHP, monosymptomatic hypochondriacal psychosis; QoL, quality of life; SSRI, selective serotonin reuptake inhibitor; SNRI, serotonin-norepinephrine reuptake inhibitor; TCA, tricyclic antidepressants. 
A more unique treatment option for this class of conditions is $\mathrm{N}$-acetylcysteine (NAC), which has shown great promise in the treatment of trichotillomania. ${ }^{125-128}$ Unlike other impulse control disorders, trichotillomania is often resistant to SSRIs, but a Cochrane review by Rothbart et al determined that NAC, as well as clomipramine and olanzapine (an antipsychotic), may be effective. ${ }^{129} \mathrm{NAC}$ is an amino acid that acts as a glutamate modulator and may exert its effects by normalizing dysregulated extracellular glutamate concentrations in the nucleus accumbens: an area of the brain that plays a key role in motivation and reward. ${ }^{126}$ The common dose of NAC for trichotillomania is $1,200 \mathrm{mg}$ /day, with few if any adverse effects reported by patients. Some argue that the apparent efficacy of NAC in trichotillomania suggests it could and should be tried for other impulse control disorders that involve scratching or picking. ${ }^{128}$

For habit-tic deformity of the nail, one clinician discovered an inexpensive and safe treatment that was effective in normalizing the nails of two patients after 3-6 months of use. ${ }^{130} \mathrm{He}$ had the patients apply cyanoacrylate adhesive (a form of instant glue) to the proximal nail fold of affected nails 1-2 times a week, effectively forming a physical barrier to external trauma. While creative, this method does not necessarily cure the patients' underlying motivation to scratch at their cuticles, and relapse can be expected and, indeed, was seen in one of the subjects. Interestingly, though, this subject reinstituted treatment until normalization of the nail again was achieved, and following subsequent discontinuation of therapy, he was able to maintain normal nails with reported resolution of his previous picking habit. As a relatively benign topical option, this may be worth trying, but it is also important to note the possibility of developing contact dermatitis in response to the cyanoacrylate. ${ }^{131-133}$

\section{Conclusion}

The intent of this review was to express how prevalent and troubling psychiatric comorbidity is for patients with dermatological disease. It is not a rarity that might oblige us to ignore learning the elements of diagnosis and treatment, but rather a widespread and mounting problem that beseeches our attention. Although most dermatologists are not mental health professionals with a breadth of training in psychotherapy and psychopharmacology, we do have the mental capacities to acquire the basic principles of these fields and to apply them for the betterment of our patients. Shedding our negative stigmas and opening our eyes and ears to the psychological struggles of our patients will not only make us better physicians, but will allow us to grow and expand our specialty in ways that will provide a huge service to our patients and our communities, in a field where the need for help is as high as ever. Implementing screening tools is essential in capturing the psychiatric comorbidity that often goes unseen in dermatology clinics, and referral to psychiatry or coordination with primary care is a great option for management, if the patient is willing. If not, starting the process of psychopharmacologic treatment falls in the hands of the dermatologist, and denial of this reality will only prolong the patient's suffering. By utilizing the information outlined in this paper (Figure 1), the hope is that dermatologists can establish an adequate degree of comfort with some of the commonly used psychotropic agents, and the process of treating each patient as a whole can begin on a grand and impactful scale.

\section{Disclosure}

The author reports no conflicts of interest in this work.

\section{References}

1. Connor CJ, Liu V, Fiedorowicz JG. Exploring the physiological link between psoriasis and mood disorders. Dermatol Res Pract. 2015; 2015:409637.

2. Ferreira BI, Abreu JL, Reis JP, Figueiredo AM. Psoriasis and associated psychiatric disorders: a systematic review on etiopathogenesis and clinical correlation. J Clin Aesthet Dermatol. 2016;9(6):36-43.

3. Koo J, Lebwohl A. Psychodermatology: the mind and skin connection. Am Fam Phys. 2001;64(11):1873-1878.

4. Gupta MA, Gupta AK. Psychodermatology: an update. J Am Acad Dermatol. 1996;34(6):1030-1046.

5. Koo JY, Pham CT. Psychodermatology. Practical guidelines on pharmacotherapy. Arch Dermatol. 1992;128(3):381-388.

6. Laupland KB, Valiquette L. Delusional infestation. Can J Infect Dis Med Microbiol. 2016;2016:9091838.

7. Bewley AP, Lepping P, Freudenmann RW, Taylor R. Delusional parasitosis: time to call it delusional infestation. Br J Dermatol. 2010;163(1): $1-2$.

8. Al-Harbi M. Prevalence of depression in vitiligo patients. Skinmed. 2013;11(6):327-330.

9. Dowlatshahi EA, Wakkee M, Arends LR, Nijsten T. The prevalence and odds of depressive symptoms and clinical depression in psoriasis patients: a systematic review and meta-analysis. J Invest Dermatol. 2014; 134(6):1542-1551.

10. Fleming P, Bai JW, Pratt M, Sibbald C, Lynde C, Gulliver WP. The prevalence of anxiety in patients with psoriasis: a systematic review of observational studies and clinical trials. J Eur Acad Dermatol Venereol. Epub 2016 Sep 12.

11. Ghajarzadeh M, Ghiasi M, Kheirkhah S. Associations between skin diseases and quality of life: a comparison of psoriasis, vitiligo, and alopecia areata. Acta Med Iran. 2012;50(7):511-515.

12. Muffadel A, Abdelgani A. Psychiatric comorbidity in patients with psoriasis, vitiligo, acne, eczema and group of patients with miscellaneous dermatological diagnoses. Open J Psychiatry. 2014;4:168-175.

13. Nguyen CM, Beroukhim K, Danesh MJ, Babikian A, Koo J, Leon A. The psychosocial impact of acne, vitiligo, and psoriasis: a review. Clin Cosmet Investig Dermatol. 2016;9:383-392.

14. Shlyankevich J, Chen AJ, Kim GE, Kimball AB. Hidradenitis suppurativa is a systemic disease with substantial comorbidity burden: a chart-verified case-control analysis. J Am Acad Dermatol. 2014 71(6):1144-1150.

15. Dalgard F, Gieler U, Holm JO, Bjertness E, Hauser S. Self-esteem and body satisfaction among late adolescents with acne: results from a population survey. J Am Acad Dermatol. 2008;59(5):746-751. 
16. Onderdijk AJ, van der Zee HH, Esmann S, et al. Depression in patients with hidradenitis suppurativa. J Eur Acad Dermatol Venereol. 2013;27(4): 473-478.

17. Sanna L, Stuart AL, Pasco JA, et al. Atopic disorders and depression: findings from a large, population-based study. JAffect Disord. 2014;155: 261-265.

18. Dalgard FJ, Gieler U, Tomas-Aragones L, et al. The psychological burden of skin diseases: a cross-sectional multicenter study among dermatological out-patients in 13 European countries. J Invest Dermatol. 2015; 135(4):984-991.

19. Rostenberg A Jr. The role of psychogenic factors in skin diseases. Arch Dermatol. 1960;81:81-86.

20. Kurd SK, Troxel AB, Crits-Christoph P, Gelfand JM. The risk of depression, anxiety, and suicidality in patients with psoriasis: a populationbased cohort study. Arch Dermatol. 2010;146(8):891-895.

21. Rapp SR, Feldman SR, Exum ML, Fleischer AB Jr, Reboussin DM. Psoriasis causes as much disability as other major medical diseases. J Am Acad Dermatol. 1999;41(3 Pt 1):401-407.

22. Balieva F, Kupfer J, Lien L, et al. The burden of common skin diseases assessed with the EQ5D: a European multi-centre study in 13 countries. Br J Dermatol. Epub 2016 Dec 29.

23. Beattie PE, Lewis-Jones MS. A comparative study of impairment of quality of life in children with skin disease and children with other chronic childhood diseases. Br J Dermatol. 2006;155(1):145-151.

24. Tollefson MM, Finnie DM, Schoch JJ, Eton DT. Impact of childhood psoriasis on parents of affected children. J Am Acad Dermatol. 2017;76(2):286-289.

25. Lee MS, Lin RY, Lai MS. Increased risk of diabetes mellitus in relation to the severity of psoriasis, concomitant medication, and comorbidity: a nationwide population-based cohort study. JAm Acad Dermatol. 2014; 70(4):691-698.

26. Wu S, Han J, Li WQ, Qureshi AA. Hypertension, antihypertensive medication use, and risk of psoriasis. JAMA Dermatol. 2014;150(9):957-963.

27. Perrott SB, Murray AH, Lowe J, Mathieson CM. The psychosocial impact of psoriasis: physical severity, quality of life, and stigmatization. Physiol Behav. 2000;70(5):567-571.

28. Richards HL, Fortune DG, Griffiths CE, Main CJ. The contribution of perceptions of stigmatisation to disability in patients with psoriasis. J Psychosom Res. 2001;50(1):11-15.

29. Takeshita J, Callis Duffin K, Shin DB, et al. Patient-reported outcomes for psoriasis patients with clear versus almost clear skin in the clinical setting. J Am Acad Dermatol. 2014;71(4):633-641.

30. Mrowietz U, Kragballe K, Reich K, et al. Definition of treatment goals for moderate to severe psoriasis: a European consensus. Arch Dermatol Res. 2011;303(1):1-10.

31. Richards HL, Fortune DG, Weidmann A, Sweeney SK, Griffiths CE. Detection of psychological distress in patients with psoriasis: low consensus between dermatologist and patient. Br J Dermatol. 2004;151(6): 1227-1233

32. Arnau RC, Meagher MW, Norris MP, Bramson R. Psychometric evaluation of the Beck Depression Inventory-II with primary care medical patients. Health Psychol. 2001;20(2):112-119.

33. Steer RA, Cavalieri TA, Leonard DM, Beck AT. Use of the Beck Depression Inventory for Primary Care to screen for major depression disorders. Gen Hosp Psychiatry. 1999;21(2):106-111.

34. Doerfler LA, Felner RD, Rowlison RT, Raley PA, Evans E. Depression in children and adolescents: a comparative analysis of the utility and construct validity of two assessment measures. J Consult Clin Psychol. 1988;56(5):769-772.

35. Timbremont B, Braet C, Dreessen L. Assessing depression in youth: relation between the Children's Depression Inventory and a structured interview. J Clin Child Adolesc Psychol. 2004;33(1):149-157.

36. Kroenke K, Spitzer RL, Williams JB. The PHQ-9: validity of a brief depression severity measure. J Gen Intern Med. 2001;16(9):606-613.

37. Kung S, Alarcon RD, Williams MD, Poppe KA, Jo Moore M, Frye MA. Comparing the Beck Depression Inventory-II (BDI-II) and Patient Health Questionnaire (PHQ-9) depression measures in an integrated mood disorders practice. J Affect Disord. 2013;145(3):341-343.
38. Schutt PE, Kung S, Clark MM, Koball AM, Grothe KB. Comparing the Beck Depression Inventory-II (BDI-II) and Patient Health Questionnaire (PHQ-9) depression measures in an outpatient bariatric clinic. Obes Surg. 2016;26(6):1274-1278.

39. Spitzer RL, Kroenke K, Williams JB, Lowe B. A brief measure for assessing generalized anxiety disorder: the GAD-7. Arch Intern Med. 2006;166(10):1092-1097.

40. Swinson RP. The GAD-7 scale was accurate for diagnosing generalised anxiety disorder. Evid Based Med. 2006;11(6):184.

41. Zigmond AS, Snaith RP. The hospital anxiety and depression scale. Acta Psychiatr Scand. 1983;67(6):361-370.

42. Bjelland I, Dahl AA, Haug TT, Neckelmann D. The validity of the Hospital Anxiety and Depression Scale. An updated literature review. J Psychosom Res. 2002;52(2):69-77.

43. Snaith RP. The Hospital Anxiety And Depression Scale. Health Qual Life Outcomes. 2003;1:29.

44. Ashcroft DM, Li Wan Po A, Williams HC, Griffiths CE. Quality of life measures in psoriasis: a critical appraisal of their quality. J Clin Pharm Ther. 1998;23(5):391-398.

45. Ali FM, Cueva AC, Vyas J, et al. A systematic review of the use of quality-of-life instruments in randomized controlled trials for psoriasis. Br J Dermatol. Epub 2016 Jun 7.

46. Basra MK, Salek MS, Camilleri L, Sturkey R, Finlay AY. Determining the minimal clinically important difference and responsiveness of the Dermatology Life Quality Index (DLQI): further data. Dermatology (Basel, Switzerland). 2015;230(1):27-33.

47. Chren MM, Lasek RJ, Quinn LM, Mostow EN, Zyzanski SJ. Skindex, a quality-of-life measure for patients with skin disease: reliability, validity, and responsiveness. J Invest Dermatol. 1996;107(5): 707-713.

48. Bronsard V, Paul C, Prey S, et al. What are the best outcome measures for assessing quality of life in plaque type psoriasis? A systematic review of the literature. J Eur Acad Dermatol Venereol. 2010;24(Supp1 2): $17-22$.

49. Gupta MA, Gupta AK. The Psoriasis Life Stress Inventory: a preliminary index of psoriasis-related stress. Acta Derm Venereol. 1995; 75(3):240-243.

50. Kent G, al-Abadie M. The Psoriasis Disability Index - further analyses. Clin Exp Dermatol. 1993;18(5):414-416.

51. Fortune DG, Main CJ, O'Sullivan TM, Griffiths CE. Assessing illnessrelated stress in psoriasis: the psychometric properties of the Psoriasis Life Stress Inventory. J Psychosom Res. 1997;42(5):467-475.

52. Finlay AY, Khan GK, Luscombe DK, Salek MS. Validation of Sickness Impact Profile and Psoriasis Disability Index in Psoriasis. Br J Dermatol. 1990;123(6):751-756.

53. Gronholm PC, Thornicroft G, Laurens KR, Evans-Lacko S. Mental health-related stigma and pathways to care for people at risk of psychotic disorders or experiencing first-episode psychosis: a systematic review. Psychol Med. Epub 2017 Feb 15.

54. Schnyder N, Panczak R, Groth N, Schultze-Lutter F. Association between mental health-related stigma and active help-seeking: systematic review and meta-analysis. Br J Psychiatry. Epub 2017 Feb 2.

55. Rubak S, Sandbaek A, Lauritzen T, Christensen B. Motivational interviewing: a systematic review and meta-analysis. Br J Gen Pract. 2005; 55(513):305-312.

56. Zomahoun HT, Guenette L, Gregoire JP, et al. Effectiveness of motivational interviewing interventions on medication adherence in adults with chronic diseases: a systematic review and meta-analysis. Int $J$ Epidemiol. Epub 2016 Nov 17.

57. Koblenzer CS, Koblenzer PJ. Chronic intractable atopic eczema. Its occurrence as a physical sign of impaired parent-child relationships and psychologic developmental arrest: improvement through parent insight and education. Arch Dermatol. 1988;124(11):1673-1677.

58. Morawska A, Mitchell AE, Burgess S, Fraser J. Effects of Triple P parenting intervention on child health outcomes for childhood asthma and eczema: randomised controlled trial. Behav Res Ther. 2016;83:35-44.

59. Williams DH. Management of atopic dermatitis in children; control of maternal rejection factor. Arch Dermatol Syphilol. 1951;63(5):545-560. 
60. Brown DG, Bettley FR. Psychiatric treatment of eczema: a controlled trial. Br Med J. 1971;2(5764):729-734.

61. Fordham B, Griffiths CE, Bundy C. A pilot study examining mindfulnessbased cognitive therapy in psoriasis. Psychol Health Med. Epub 2014 Apr 1.

62. Fortune DG, Richards HL, Kirby B, Bowcock S, Main CJ, Griffiths CE. A cognitive-behavioural symptom management programme as an adjunct in psoriasis therapy. Br J Dermatol. 2002;146(3):458-465.

63. Altaf K, Mohandas P, Marshall C, Taylor R, Bewley A. Managing patients with delusional infestations in an integrated psychodermatology clinic is much more cost effective than a general dermatology or primary care setting. Br J Dermatol. Epub 2016 Sep 28.

64. Bewley AP. Delusional infestation. Presented at: American Academy of Dermatology Annual Meeting; March 5, 2017; Orlando, FL.

65. Freudenmann RW, Lepping P. Second-generation antipsychotics in primary and secondary delusional parasitosis: outcome and efficacy. J Clin Psychopharmacol. 2008;28(5):500-508.

66. Houghton DC, Maas J, Twohig MP, et al. Comorbidity and quality of life in adults with hair pulling disorder. Psychiatry Res. 2016;239:12-19.

67. Juergens S. Alprazolam and diazepam: addiction potential. J Subst Abuse Treat. 1991;8(1-2):43-51.

68. Remick RA, Keller FD, Buchanan RA, Gibson RE, Fleming JA. A comparison of the efficacy and safety of alprazolam and desipramine in depressed outpatients. Can J Psychiatry. 1988;33(7):590-594.

69. Singh AN, Nair NP, Suranyi-Cadotte B, Schwartz G, Lizondo E. A double blind comparison of alprazolam and amitriptyline hydrochloride in the treatment of nonpsychotic depression. Can J Psychiatry. 1988;33(3):218-222.

70. Warner MD, Peabody CA, Whiteford HA, Hollister LE. Alprazolam as an antidepressant. J Clin Psychiatry. 1988;49(4):148-150.

71. Wang SM, Kim JB, Sakong JK, et al. The efficacy and safety of clonazepam in patients with anxiety disorder taking newer antidepressants: a multicenter naturalistic study. Clin Psychopharmacol Neurosci. 2016; 14(2):177-183.

72. Uhlenhuth EH. "Buspirone: a clinical review of a new, non-benzodiazepine anxiolytic". J Clin Psychiatry. 1982;43(12 Pt 2):109-116.

73. Gammans RE, Mayol RF, Mackenthun AV, Sokya LF. The relationship between buspirone bioavailability and dose in healthy subjects. Biopharm Drug Dispos. 1985;6(2):139-145.

74. Tiller JW. The new and newer antianxiety agents. Med J Aust. 1989; 151(11-12):697-701.

75. Kavan MG, Elsasser G, Barone EJ. Generalized anxiety disorder: practical assessment and management. Am Fam Phys. 2009;79(9):785-791.

76. Bielski RJ, Bose A, Chang CC. A double-blind comparison of escitalopram and paroxetine in the long-term treatment of generalized anxiety disorder. Ann Clin Psychiatry. 2005;17(2):65-69.

77. Davidson JR, Bose A, Korotzer A, Zheng H. Escitalopram in the treatment of generalized anxiety disorder: double-blind, placebo controlled, flexible-dose study. Depress Anxiety. 2004;19(4):234-240.

78. Davidson JR, Bose A, Wang Q. Safety and efficacy of escitalopram in the long-term treatment of generalized anxiety disorder. J Clin Psychiatry. 2005;66(11):1441-1446.

79. Harris BA, Sherertz EF, Flowers FP. Improvement of chronic neurotic excoriations with oral doxepin therapy. Int J Dermatol. 1987;26(8):541-543.

80. Figueiredo A, Ribeiro CA, Goncalo M, Almeida L, Poiares-Baptista A, Teixeira F. Mechanism of action of doxepin in the treatment of chronic urticaria. Fundam Clin Pharmacol. 1990;4(2):147-158.

81. Lawlor F, Greaves MW. Die Entwicklung neuer Strategien der Urticariathera - pie als ein Ergebnis klinisch orientierter Forschung [The development of recent strategies in the treatment of urticaria as a result of clinically oriented research]. Zeitschrift fur Hautkrankheiten. 1990;65(1):17-27. Danish.

82. Rao KS, Menon PK, Hilman BC, Sebastian CS, Bairnsfather L. Duration of the suppressive effect of tricyclic antidepressants on histamine-induced wheal-and-flare reactions in human skin. J Allergy Clin Immunol. 1988;82(5 Pt 1):752-757.

83. Leucht S, Steimer W, Kreuz S, Abraham D, Orsulak PJ, Kissling W. Doxepin plasma concentrations: is there really a therapeutic range? J Clin Psychopharmacol. 2001;21(4):432-439.
84. Ward NG, Bloom VL, Wilson L, Raskind M, Raisys VA. Doxepin plasma levels and therapeutic response in depression: preliminary findings. J Clin Psychopharmacol. 1982;2(2):126-128.

85. Entsuah R, Upton GV, Rudolph R. Efficacy of venlafaxine treatment in depressed patients with psychomotor retardation or agitation: a metaanalysis. Human Psychopharmacol. 1995;10(3):195-200.

86. Singh AB, Bousman CA, Ng CH, Byron K, Berk M. Psychomotor depressive symptoms may differentially respond to venlafaxine. Int Clin Psychopharmacol. 2013;28(3):121-126.

87. Baghai TC, Eser D, Moller HJ. Effects of different antidepressant treatments on the core of depression. Dialogues Clin Neurosci. 2008;10(3): 309-320.

88. Cipriani A, Furukawa TA, Salanti G, et al. Comparative efficacy and acceptability of 12 new-generation antidepressants: a multipletreatments meta-analysis. Lancet. 2009;373(9665):746-758.

89. Flament MF, Lane RM, Zhu R, Ying Z. Predictors of an acute antidepressant response to fluoxetine and sertraline. Int Clin Psychopharmacol. 1999;14(5):259-275.

90. Gupta RK, Moller HJ. St. John's Wort. An option for the primary care treatment of depressive patients? Eur Arch Psychiatry Clin Neurosci. 2003;253(3):140-148.

91. Kasper S. Hypericum perforatum - a review of clinical studies. Pharmacopsychiatry. 2001;34(Suppl 1):S51-S55.

92. Laakmann G, Schule C, Baghai T, Kieser M. St. John's wort in mild to moderate depression: the relevance of hyperforin for the clinical efficacy. Pharmacopsychiatry. 1998;31(Suppl 1):54-59.

93. Uebelhack R, Gruenwald J, Graubaum HJ, Busch R. Efficacy and tolerability of hypericum extract STW 3-VI in patients with moderate depression: a double-blind, randomized, placebo-controlled clinical trial. Adv Ther. 2004;21(4):265-275.

94. Markowitz JS, Donovan JL, DeVane CL, et al. Effect of St John's wort on drug metabolism by induction of cytochrome P450 3A4 enzyme. JAMA. 2003;290(11):1500-1504.

95. Levin EC, Gieler U. Delusions of parasitosis. Semin Cutan Med Surg. 2013;32(2):73-77.

96. Munro A. Monosymptomatic hypochondriacal psychosis. Br J Psychiatry Suppl. 1988;(2):37-40.

97. Patel V, Koo JY. Delusions of parasitosis; suggested dialogue between dermatologist and patient. J Dermatolog Treat. 2015;26(5):456-460.

98. Flann S, Shotbolt J, Kessel B, et al. Three cases of delusional parasitosis caused by dopamine agonists. Clin Exp Dermatol. 2010; 35(7):740-742.

99. Kolle M, Lepping P, Kassubek J, Schonfeldt-Lecuona C, Freudenmann RW. Delusional infestation induced by piribedil add-on in Parkinson's disease. Pharmacopsychiatry. 2010;43(6):240-242.

100. Marshall CL, Williams V, Ellis C, Taylor RE, Bewley AP. Delusional infestation may be caused by recreational drug usage in some patients, but they may not disclose their habit. Clin Exp Dermatol. 2017; 42(1):41-45.

101. Avnstorp C, Hamann K, Jepsen PW. Parasitforrykthed behandlet med pimozid (Orap) [Delusions of parasite infestation treated with pimozide (Orap)]. Ugeskrift for laeger. 1980;142(34):2191-2192. German.

102. Damiani JT, Flowers FP, Pierce DK. Pimozide in delusions of parasitosis. J Am Acad Dermatol. 1990;22(2 Pt 1):312-313.

103. Hamann K, Avnstorp C. Delusions of infestation treated by pimozide: a double-blind crossover clinical study. Acta Derm Venereol. 1982;62(1): $55-58$.

104. Lorenzo CR, Koo J. Pimozide in dermatologic practice: a comprehensive review. Am J Clin Dermatol. 2004;5(5):339-349.

105. Winslow RS, Stillner V, Coons DJ, Robison MW. Prevention of acute dystonic reactions in patients beginning high-potency neuroleptics. Am J Psychiatry. 1986;143(6):706-710.

106. Huber M, Lepping P, Pycha R, Karner M, Schwitzer J, Freudenmann RW. Delusional infestation: treatment outcome with antipsychotics in 17 consecutive patients (using standardized reporting criteria). Gen Hosp Psychiatry. 2011;33(6):604-611.

107. Trabert W. 100 years of delusional parasitosis. Meta-analysis of 1,223 case reports. Psychopathology. 1995;28(5):238-246. 
108. Huang WL, Chang LR. Aripiprazole in the treatment of delusional parasitosis with ocular and dermatologic presentations. J Clin Psychopharmacol. 2013;33(2):272-273.

109. Ladizinski B, Busse KL, Bhutani T, Koo JY. Aripiprazole as a viable alternative for treating delusions of parasitosis. J Drugs Dermatol. 2010; 9(12):1531-1532.

110. Bak M, Fransen A, Janssen J, van Os J, Drukker M. Almost all antipsychotics result in weight gain: a meta-analysis. PLoS One. 2014; 9(4):e94112.

111. Barak N, Beck Y, Albeck JH. A randomized, double-blind, placebo-controlled pilot study of betahistine to counteract olanzapine-associated weight gain. J Clin Psychopharmacol. 2016;36(3):253-256.

112. Barak N, Beck Y, Albeck JH. Betahistine decreases olanzapineinduced weight gain and somnolence in humans. J Psychopharmacol. 2016;30(3):237-241.

113. Lian J, Huang XF, Pai N, Deng C. Ameliorating antipsychotic-induced weight gain by betahistine: mechanisms and clinical implications. Pharmacol Res. 2016;106:51-63.

114. Wong S, Bewley A. Patients with delusional infestation (delusional parasitosis) often require prolonged treatment as recurrence of symptoms after cessation of treatment is common: an observational study. Br J Dermatol. 2011;165(4):893-896.

115. Brakoulias V. Managing obsessive compulsive disorder. Aust Prescr. 2015;38(4):121-123.

116. Ost LG, Riise EN, Wergeland GJ, Hansen B, Kvale G. Cognitive behavioral and pharmacological treatments of OCD in children: a systematic review and meta-analysis. J Anxiety Disord. 2016;43: 58-69.

117. Wootton BM. Remote cognitive-behavior therapy for obsessivecompulsive symptoms: a meta-analysis. Clin Psychol Rev. 2016;43: $103-113$.

118. Katz RJ, DeVeaugh-Geiss J, Landau P. Clomipramine in obsessivecompulsive disorder. Biol Psychiatry. 1990;28(5):401-414.

119. Leonard H, Swedo S, Rapoport JL, Coffey M, Cheslow D. Treatment of childhood obsessive compulsive disorder with clomipramine and desmethylimipramine: a double-blind crossover comparison. Psychopharmacol Bull. 1988;24(1):93-95.
120. Leonard HL, Lenane MC, Swedo SE, Rettew DC, Rapoport JL. A double-blind comparison of clomipramine and desipramine treatment of severe onychophagia (nail biting). Arch Gen Psychiatry. 1991;48(9): 821-827.

121. Swedo SE, Leonard HL, Rapoport JL, Lenane MC, Goldberger EL, Cheslow DL. A double-blind comparison of clomipramine and desipramine in the treatment of trichotillomania (hair pulling). NEngl J Med. 1989;321(8):497-501.

122. Peters MD 2nd, Davis SK, Austin LS. Clomipramine: an antiobsessional tricyclic antidepressant. Clin Pharm. 1990;9(3):165-178.

123. Pigott TA, Pato MT, Bernstein SE, et al. Controlled comparisons of clomipramine and fluoxetine in the treatment of obsessive-compulsive disorder. Behavioral and biological results. Arch Gen Psychiatry. 1990;47(10):926-932.

124. Vittorio CC, Phillips KA. Treatment of habit-tic deformity with fluoxetine. Arch Dermatol. 1997;133(10):1203-1204.

125. Goulding JM. N-acetylcysteine in trichotillomania: further thoughts. Br J Dermatol. 2015;172(6):1683-1684.

126. Grant JE, Odlaug BL, Kim SW. N-acetylcysteine, a glutamate modulator, in the treatment of trichotillomania: a double-blind, placebocontrolled study. Arch Gen Psychiatry. 2009;66(7):756-763.

127. Ozcan D, Seckin D. N-Acetylcysteine in the treatment of trichotillomania: remarkable results in two patients. JEur Acad Dermatol Venereol. 2016;30(9):1606-1608.

128. Taylor M, Bhagwandas K. N-acetylcysteine in trichotillomania: a panacea for compulsive skin disorders? Br J Dermatol. 2014;171(5):1253-1255.

129. Rothbart R, Amos T, Siegfried N, et al. Pharmacotherapy for trichotillomania. Cochrane Database Syst Rev. 2013;11:Cd007662.

130. Ring DS. Inexpensive solution for habit-tic deformity. Arch Dermatol. 2010;146(11):1222-1223.

131. Bowen C, Bidinger J, Hivnor C, Hoover A, Henning JS. Allergic contact dermatitis to 2-octyl cyanoacrylate. Cutis. 2014;94(4):183-186.

132. Davis MD, Stuart MJ. Severe allergic contact dermatitis to dermabond prineo, a topical skin adhesive of 2-octyl cyanoacrylate increasingly used in surgeries to close wounds. Dermatitis. 2016;27(2):75-76.

133. Lefevre S, Valois A, Truchetet F. Allergic contact dermatitis caused by Dermabond((R)). Contact Dermatitis. 2016;75(4):240-241.
Clinical, Cosmetic and Investigational Dermatology

\section{Publish your work in this journal}

Clinical, Cosmetic and Investigational Dermatology is an international, peer-reviewed, open access, online journal that focuses on the latest clinical and experimental research in all aspects of skin disease and cosmetic interventions. This journal is included on PubMed. The manuscript management system is completely online

\section{Dovepress}

and includes a very quick and fair peer-review system, which is all easy to use. Visit http://www.dovepress.com/testimonials.php to read real quotes from published authors 